\title{
Design of S-substituted Fluorinated Aryl Sulfonamide Tagged (S-FAST) anions to enable new solvate ionic liquids for battery applications
}

\author{
Mingjun Huang, $\dagger^{\mathrm{a}}$ Shuting Feng, $\dagger^{\mathrm{b}}$ Wenxu Zhang, ${ }^{\mathrm{a}}$ Jeffrey Lopez, ${ }^{\mathrm{c}}$ Bo Qiao, ${ }^{\mathrm{a}, \mathrm{c}}$ Ryoichi Tatara, ${ }^{\mathrm{c}}$ Livia Giordano, ${ }^{\mathrm{c}, \mathrm{d}}$ \\ Yang Shao-Horn ${ }^{\star c, d}$ and Jeremiah A. Johnson*a \\ a. Department of Chemistry, Massachusetts Institute of Technology, 77 Massachusetts Avenue, Cambridge, MA 02139, U.S.A. \\ b. Department of Chemical Engineering, Massachusetts Institute of Technology, 77 Massachusetts Avenue, Cam-bridge, MA 02139, \\ United States \\ c. Research Laboratory of Electronics, Massachusetts Institute of Technology, 77 Massachusetts Avenue, Cam-bridge, MA 02139 , \\ United States \\ d. Department of Mechanical Engineering, Massachusetts Institute of Technology, 77 Massachusetts Avenue, Cam-bridge, MA 02139, \\ United States \\ † M.H. and S.F. contributed equally. \\ *Correspondence to: shaohorn@mit.edu, jaj2109@mit.edu
}

\section{Theoretical calculations}

All calculations were performed employing the Gaussian 09 computational package. ${ }^{1}$ Geometries were optimized at the B3LYP/6-31G $(d, p)^{2,3}$ level of theory; ground states were verified by the absence of any imaginary frequency. Single point energy calculations were performed at the B3LYP/6-311++G(d,p) level of theory for oxidation energies and cationanion association free energies. ${ }^{4,5}$ The conductor-like polarizable continuum model (CPCM ${ }^{6,7}$ was employed to capture solvation effects. Electrochemical oxidative stability is estimated by oxidation energy calculations, which is the Gibbs free energy for the electrochemical oxidation reaction $\mathrm{M} \rightarrow \mathrm{M}^{+}+\mathrm{e}^{-}$in the solution (Dimethyl sulfoxide (DMSO) was selected as the universal solvent in the electrochemical oxidation energy calculations):

$$
\mathrm{G}_{\mathrm{Ox}}=\mathrm{G}\left(\mathrm{M}^{+}\right)-\mathrm{G}(\mathrm{M})
$$

The computed electrochemical oxidation energy, $\mathrm{G}_{\mathrm{Ox}}$, in $\mathrm{eV}$ is converted to the experimentally measured scale versus $\mathrm{Li} / \mathrm{Li}^{+}$by the subtraction of $1.4 \mathrm{~V} .{ }^{8,9}$ To mimic the solvation environment in 1,2-dimethoxyethane (DME) solvent, diethylether was selected as the implicit solvent in the association free energy calculation, and the dielectric constant of the implicit solvent was set to 7.2. The likelihood of cation-anion interaction was estimated by the Gibbs free energy of the reaction $\mathrm{M}^{+}+\mathrm{A}^{-} \rightarrow \mathrm{MA}(\mathrm{M}=\mathrm{Na}$ or $\mathrm{Li})$, which is taken to be the association free energy in the solution:

$$
\Delta \mathrm{G}_{\text {asso }}=\mathrm{G}(\mathrm{MA})-\mathrm{G}\left(\mathrm{M}^{+}\right)-\mathrm{G}\left(\mathrm{A}^{-}\right)
$$

$\mathrm{G}\left(\mathrm{M}^{+}\right)$is approximated using the solvation of $\mathrm{M}^{+}$in $\mathrm{DME}$, more specifically,

$$
\mathrm{G}\left(\mathrm{M}^{+}\right)=\mathrm{G}_{\mathrm{gas}}\left(\mathrm{M}^{+}\right)+\Delta \mathrm{G}_{\mathrm{sol}}\left(\mathrm{M}^{+}\right)+\mathrm{RT} \ln (24.46)
$$

where $\Delta \mathrm{G}_{\mathrm{sol}}\left(\mathrm{M}^{+}\right)$is the solvation energy of $\mathrm{M}^{+}$in $\mathrm{DME}$, and its value was taken from a computational study ${ }^{10}$ where three explicit DME molecules were considered. $\mathrm{G}_{\text {gas }}\left(\mathrm{M}^{+}\right)$is the gas-phase free energy of $\mathrm{M}^{+}$and its value was computed using the same methods/basis sets. The term RTIn(24.46) converts a gas-phase reference state of 1 atm to a liquid-phase reference state of $1 \mathrm{M}$. We note that the values of $\mathrm{G}\left(\mathrm{M}^{+}\right)$obtained using this method are similar to those directly computed using an implicit solvation model.

\section{${ }^{23} \mathrm{Na}$ NMR measurement of interaction between anions and cations among S-FAST salts}

S-FAST salts were dissolved in acetonitrile $(A C N)$ to prepare $0.1 \mathrm{M}$ solution and loaded into thin wall NMR tube. The inner reference was a $0.5 \mathrm{M} \mathrm{D}_{2} \mathrm{O}$ solution of sodium perchlorate. For measurements, the reference solution was placed in a capillary sealed by PTFE cap and inserted coaxially into the sample NMR tube. The ${ }^{23} \mathrm{Na}$ spectra were collected using a Bruker $106 \mathrm{MHz}$ instrument; the chemical shift of the reference was set to $0 \mathrm{ppm}$.

Fourier-Transform Infrared Spectroscopy (FT-IR) 
FT-IR spectra were recorded on a Thermo Scientific Nicolet 6700 spectrometer using the attenuated total reflectance (ATR) technique with a Ge crystal and the Omnic software package.

\section{Thermogravimetric analysis (TGA)}

TGA was performed using a TA Instruments Discovery TGA. Samples were run in platinum TGA pans at a ramp rate of $10{ }^{\circ} \mathrm{C}$ per minute from 30 to $600{ }^{\circ} \mathrm{C}$.

\section{Kinetic Modeling:}

Equations 1 and 2 in the main text yield the following system of differential equations:

$$
\begin{gathered}
\frac{\mathrm{d}}{\mathrm{dt}}[\mathrm{SIL}]=-\mathrm{k}_{1}[\mathrm{SIL}]+\mathrm{k}_{2}\left[\mathrm{G} 4_{1, \text { free }}\right][[\mathrm{Li}][\text { anion }]] \\
\frac{\mathrm{d}}{\mathrm{dt}}\left[\mathrm{G} 4_{1, \text { free }}\right]=\mathrm{k}_{1}[\mathrm{SIL}]-\mathrm{k}_{2}\left[\mathrm{G} 4_{1, \text { free }}\right][[\mathrm{Li}][\text { anion }]]-k_{3}\left[\mathrm{G} 4_{l, \text { free }}\right] \\
\frac{d}{d t}[[\mathrm{Li}][\text { anion }]]=k_{1}[S I L]-\mathrm{k}_{2}\left[\mathrm{G} 4_{1, \text { free }}\right][[\mathrm{Li}][\text { anion }]] \\
\frac{\mathrm{d}}{\mathrm{dt}}\left[\mathrm{G} 4_{\mathrm{g}}\right]=\mathrm{k}_{3}\left[\mathrm{G} 4_{\mathrm{l}, \text { free }}\right]
\end{gathered}
$$

These equations are fit numerically to isothermal TGA data collected at $120{ }^{\circ} \mathrm{C}$ using a non-linear least-squared solver optimizing the rate constants $k_{1}, k_{2}, k_{3}$, and initial tetraglyme (G4) concentration and comparing the solved system of differential equations to the experimental data (Table S2). A constant density of $1.4 \mathrm{mg} / \mathrm{mL}^{11}$ was assumed in all mixtures. Data at $t \geq 11.5 \mathrm{~min}$ were used in the fitting to ensure temperature equilibrium. Matlab code used to fit the experimental data to the differential equations is available in the Appendix. A comparison of the experimental data and solutions to the system of differential equations using the optimized parameters and the residuals of the experimental and solved TGA data are plotted in Figure S6. 

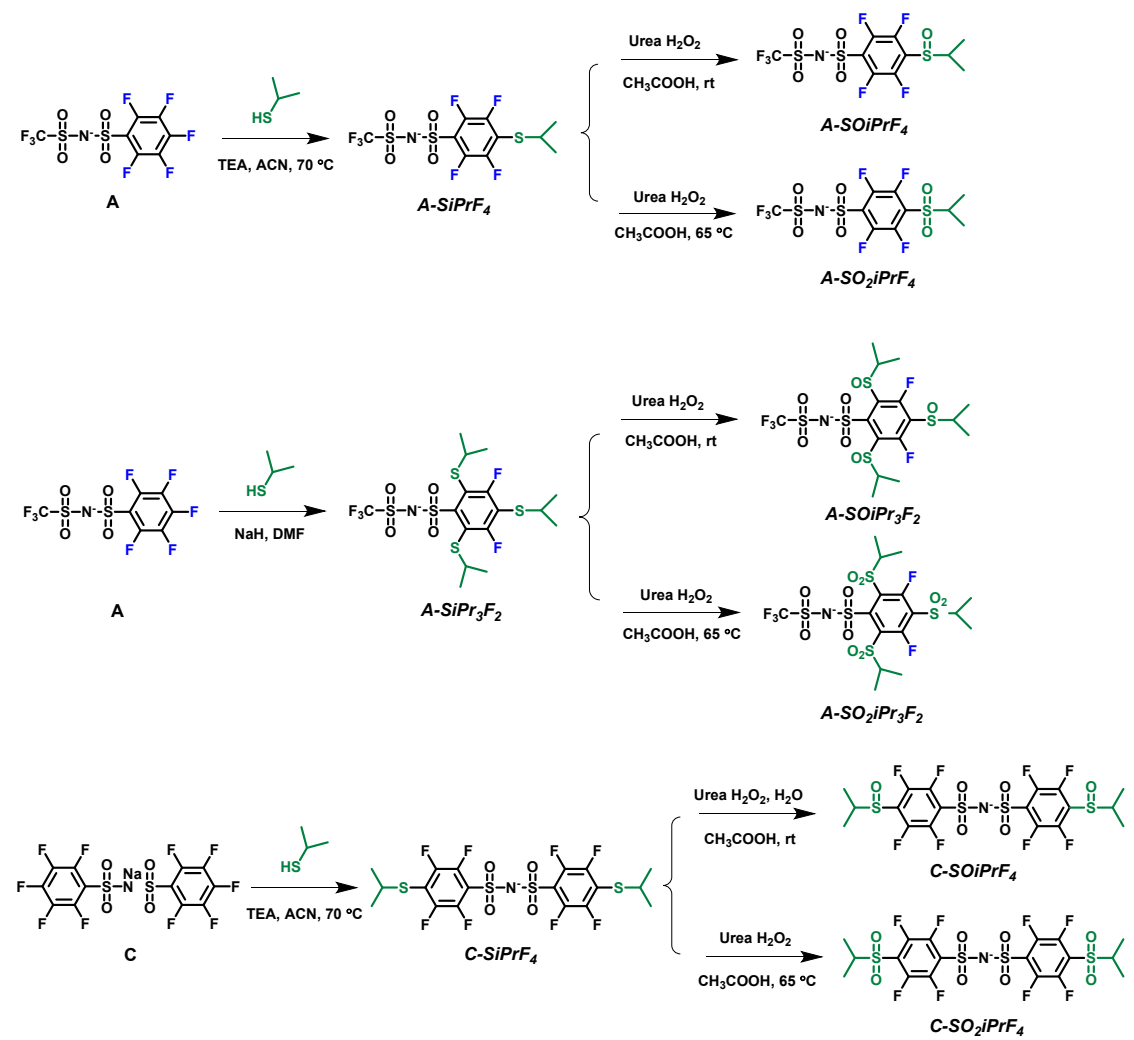

Scheme S1. Synthesis of S-FAST anions with different numbers of sulfide, sulfoxide, and sulfone substituents. 
(a)

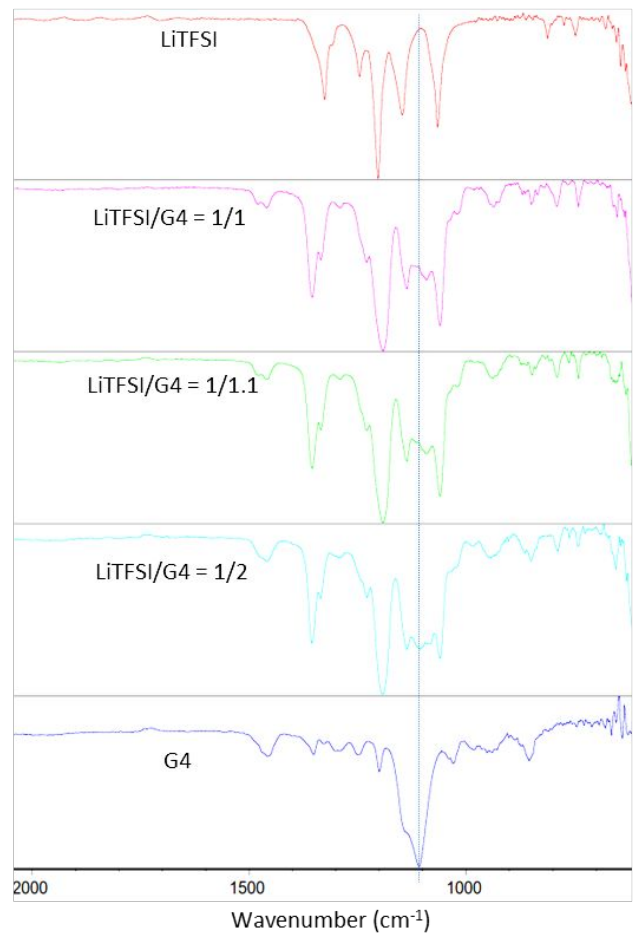

(b)

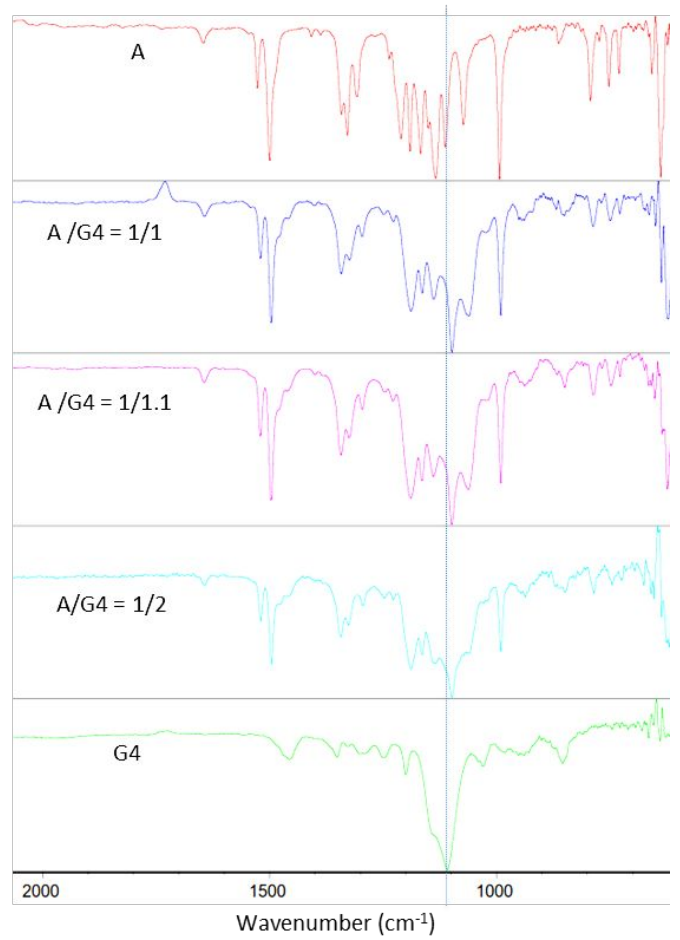

Figure S1. ATR FTIR spectra for LiTFSI/G4 mixture (a) and FAST salt A/G4 mixture (b).

(a)

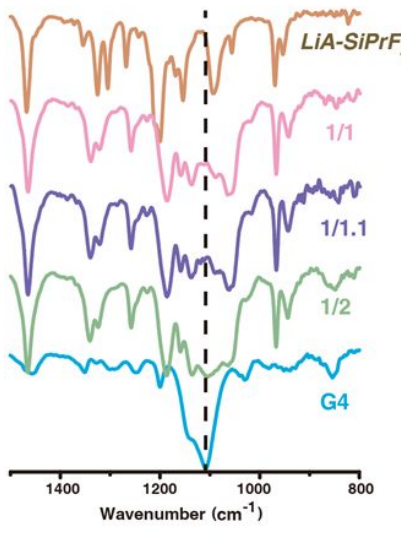

(b)

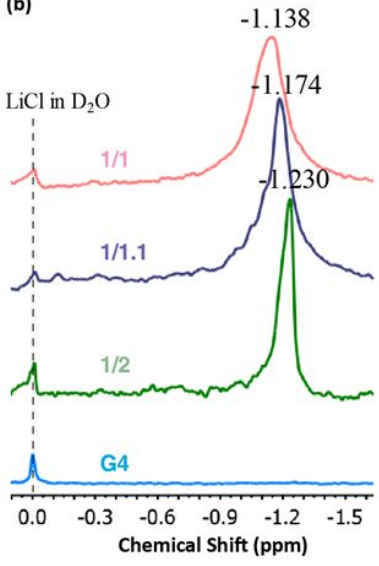

(c)

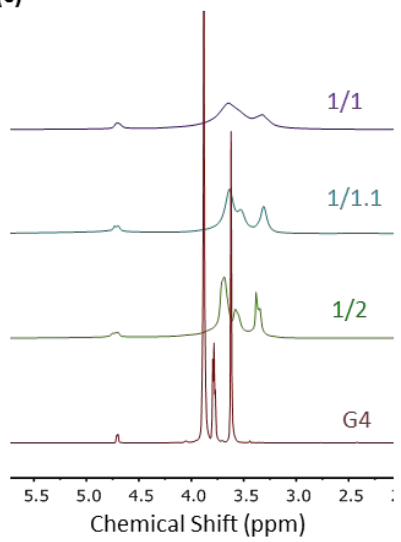

Figure S2. (a) ATR FTIR spectra for $A-\mathrm{SiPrF}_{4}, \mathrm{G} 4$, and corresponding mixtures with different ratios of salt to G4. The missing or largely suppressed peak of $\mathrm{G} 4\left(1109 \mathrm{~cm}^{-1}\right)$ in $A-S_{i P r F} / \mathrm{G} 41 / 1$ mixture suggest coordination of G4 with FAST salt. (b) ${ }^{7} \mathrm{Li} \mathrm{NMR}$ and (c) ${ }^{1} \mathrm{H}$ NMR spectra for $A-\mathrm{SiPrF}_{4}, \mathrm{G} 4$, and corresponding mixtures with different ratios of salt to G4. 

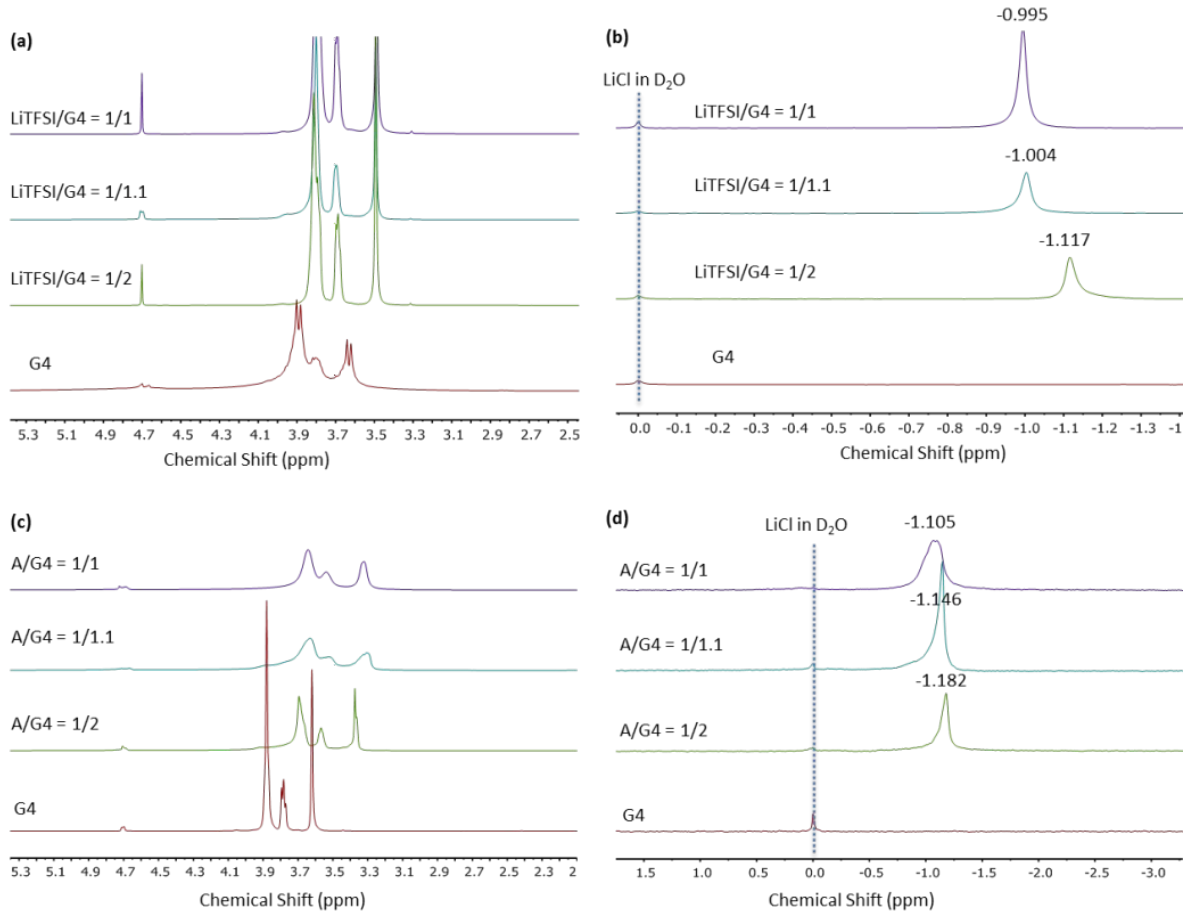

Figure S3. ${ }^{1} \mathrm{H}$ NMR and ${ }^{7} \mathrm{Li}$ NMR spectra for LiTFSI/G4 mixtures (a, b) and FAST salt A/G4 mixtures (c, d). 


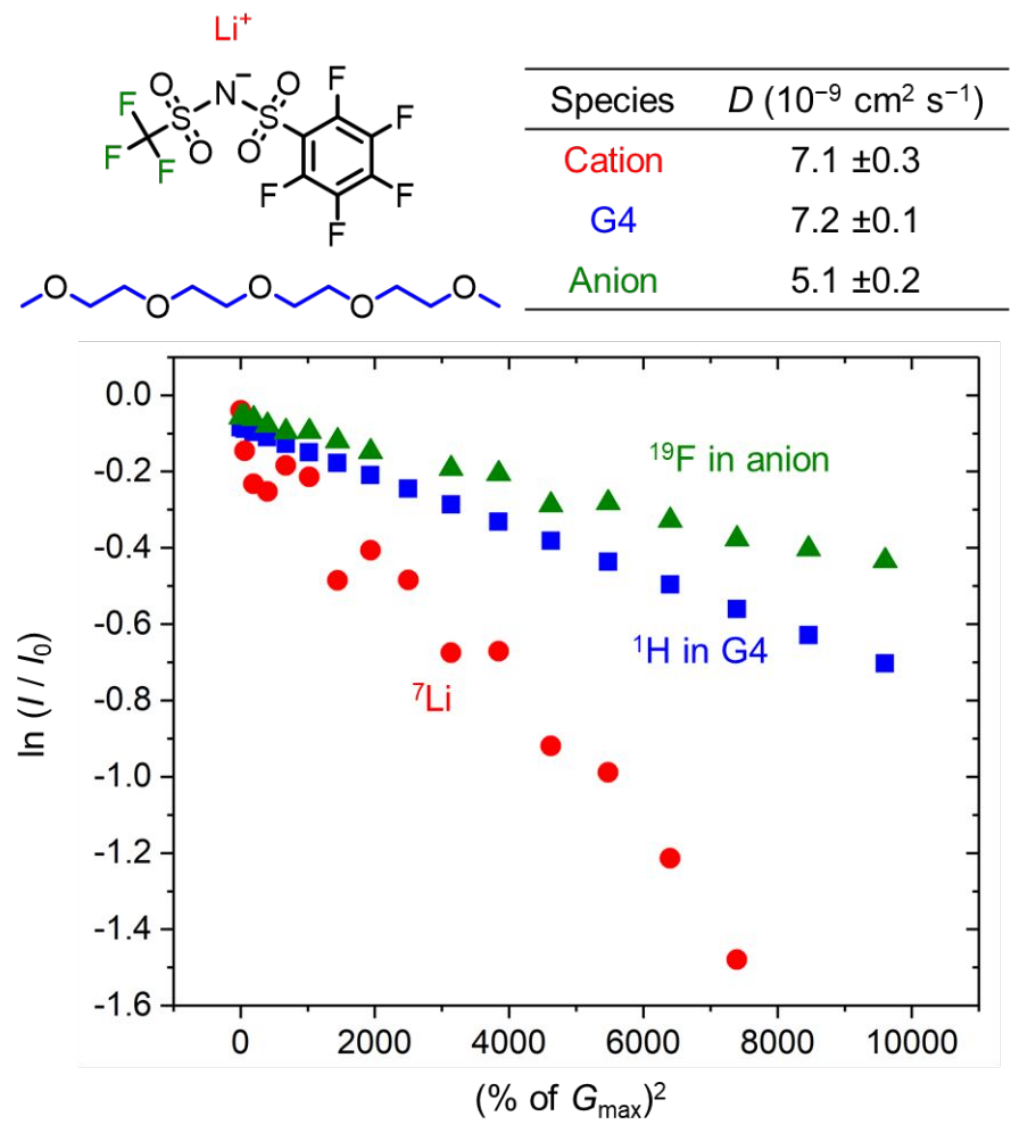

Figure S4. NMR peak intensity of an equimolar mixture of $\mathbf{A}$ and $\mathrm{G} 4\left(298 \mathrm{~K}, 500 \mathrm{MHz}\right.$ for $\left.{ }^{1} \mathrm{H}\right)$ as a function of the strength of applied gradient and diffusion co-efficients obtained from linear fitting. For ${ }^{1} \mathrm{H}, \Delta=0.5 \mathrm{~s}, \delta=0.01 \mathrm{~s}$; For ${ }^{19} \mathrm{~F}$, $\Delta=0.5 \mathrm{~s}, \delta=0.01 \mathrm{~s}$; For ${ }^{7} \mathrm{Li}, \Delta=1 \mathrm{~s}, \delta=0.03 \mathrm{~s}$, where $\Delta$ is the diffusion delay and $\delta$ is the gradient length of the experiments. $G_{\max }=5.0 \times 10^{3} \mathrm{G} \mathrm{m}^{-1}$. Errors in $D$ were estimated based on the linear fitting. 


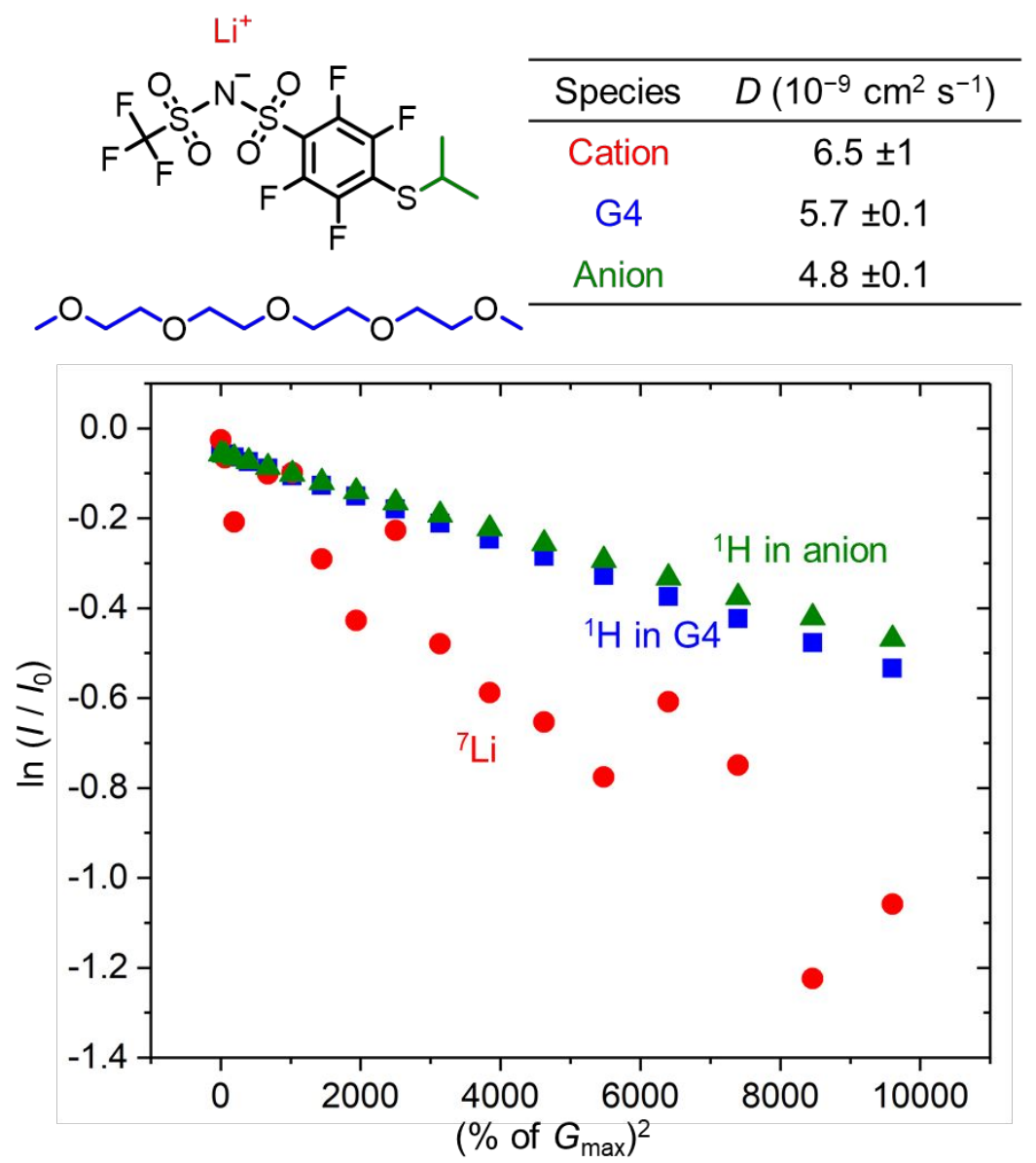

Figure S5. NMR peak intensity of an equimolar mixture of $A-S_{i P r F} / G 4$ and $\mathrm{G} 4\left(298 \mathrm{~K}, 500 \mathrm{MHz}\right.$ for $\left.{ }^{1} \mathrm{H}\right)$ as a function of the strength of applied gradient and diffusion co-efficients obtained from linear fitting of the data. For ${ }^{1} \mathrm{H}, \Delta=0.5 \mathrm{~s}$, $\delta=0.01 \mathrm{~s}$; For ${ }^{7} \mathrm{Li}, \Delta=0.7 \mathrm{~s}, \delta=0.03 \mathrm{~s}$, where $\Delta$ is the diffusion delay and $\delta$ is the gradient length of the experiments. $G_{\max }=5.0 \times 10^{3} \mathrm{G} \mathrm{m}^{-1}$. Errors in $D$ were estimated based on the linear fitting. 
a)
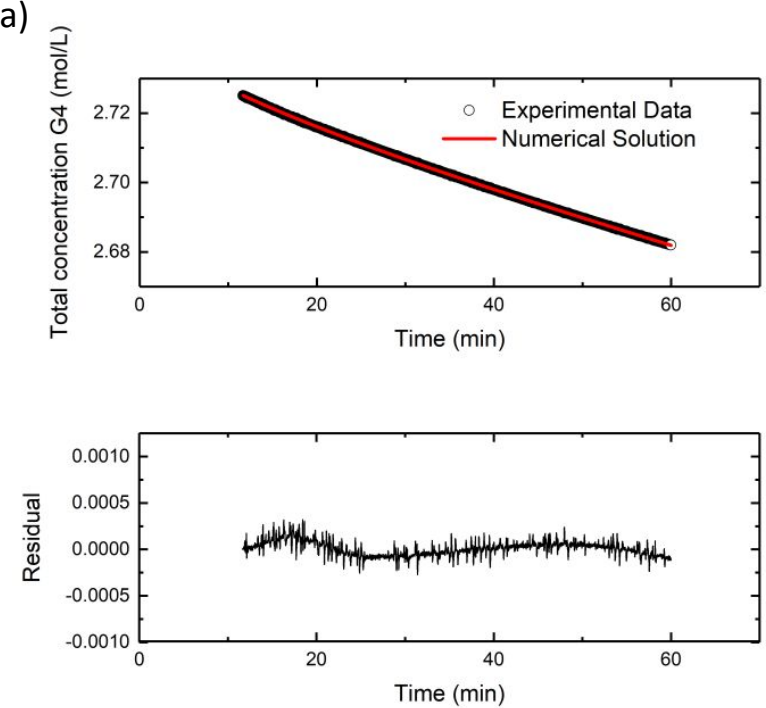

c)
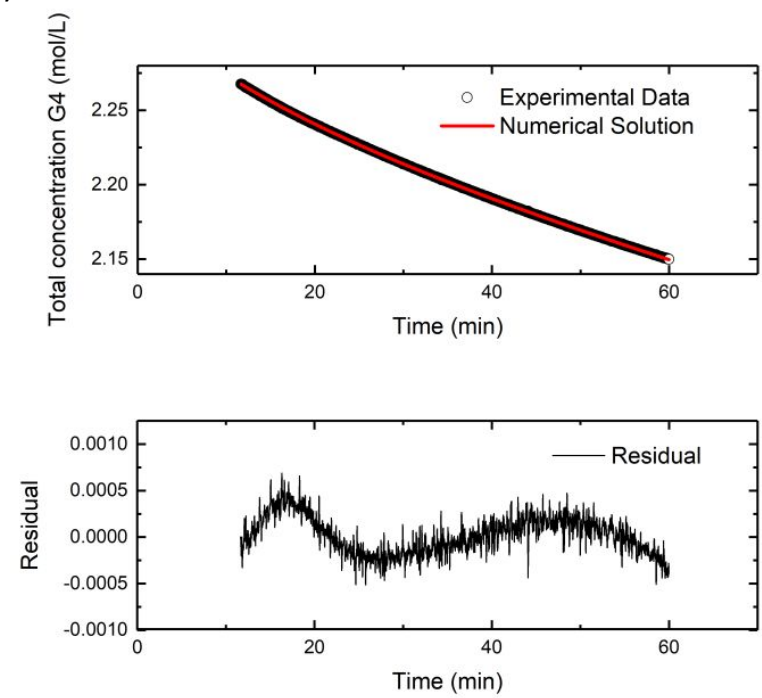

b)
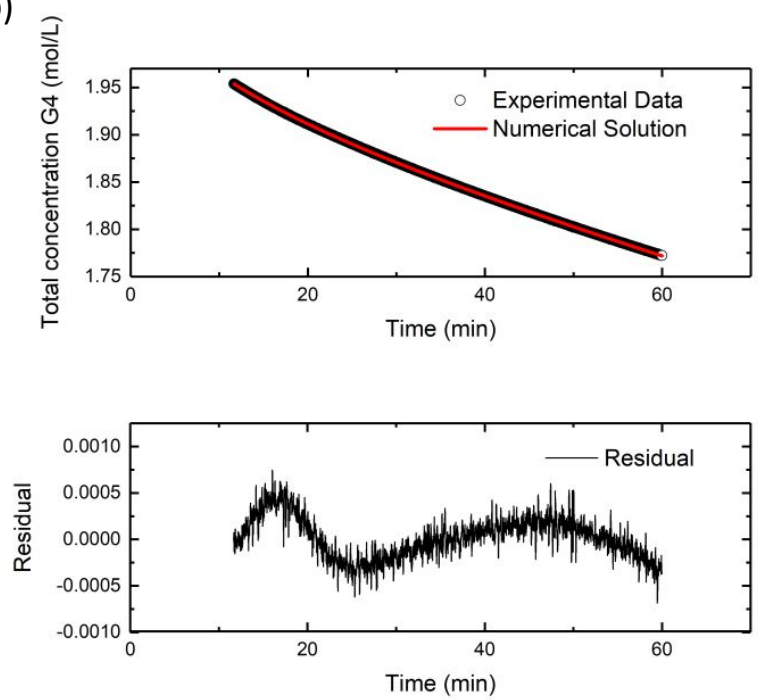

d)
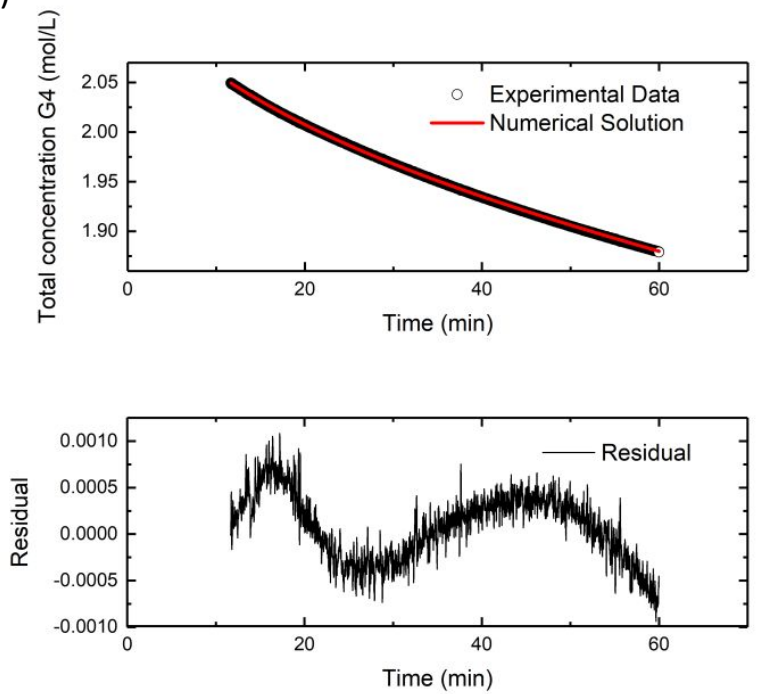

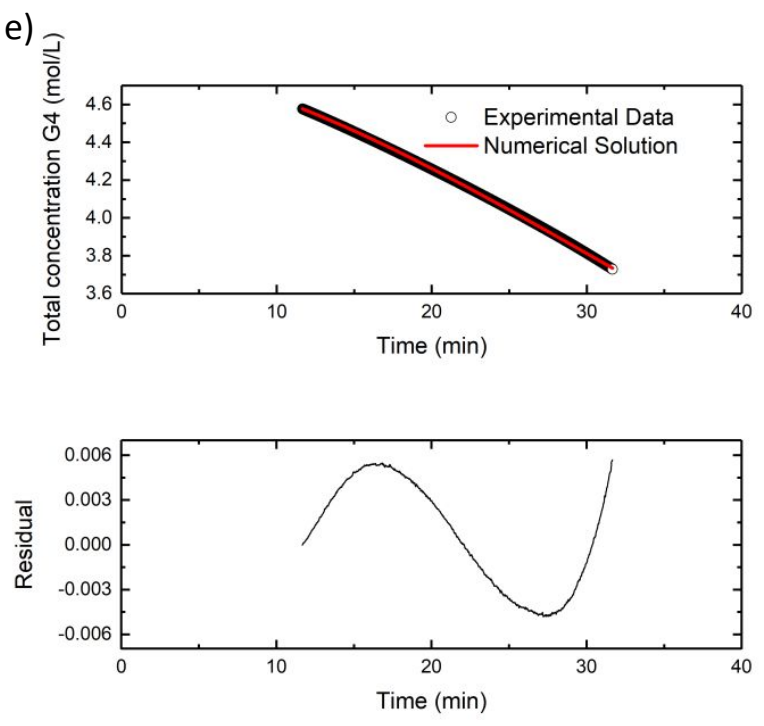

Figure S6. Numerical solution to the system of differential equations and the experimental data for the total G4 concentration, $\left[\mathrm{G}_{\mathrm{l}}\right.$,rree $]+[\mathrm{SIL}]$, and the residual of the difference between the numerical solution and experimental data for (a) [Li(G4)][TFSI], (b) [Li(G4)][A-SO $\left.\mathrm{SPrF}_{4}\right]$, (c) [Li(G4)][A], (d) [Li(G4)][ $\left.A-\mathrm{SiPrF}_{4}\right]$, and (e) [Li(G4)][NO $\left.{ }_{3}\right]$.

Table S1. Hammett Substituent Constants, $\sigma_{\text {para }}$, based on the ionization of benzoic acids. ${ }^{12,13}$

\begin{tabular}{cc}
\hline \hline Substitute & $\sigma_{\text {para }}$ \\
\hline $\mathrm{SCH}_{3}$ & 0.00 \\
$\mathrm{SCH}(\mathrm{CH} 3)_{2}$ & 0.07 \\
$\mathrm{SOCH}_{3}$ & 0.49 \\
$\mathrm{SO}_{2} \mathrm{CH}_{3}$ & 0.72 \\
$\mathrm{OCH}\left(\mathrm{CH}_{3}\right)_{2}$ & -0.45 \\
$\mathrm{~N}\left(\mathrm{CH}_{3}\right)_{2}$ & -0.83 \\
$\mathrm{~F}$ & 0.062 \\
\hline
\end{tabular}

Table S2. Numerical solutions of the initial mole fraction of free G4 as well as $k_{1}, k_{2}$, and $k_{3}$ from Eq (3) and (4) in different equimolar mixtures of $\mathrm{G} 4$ and $\mathrm{Li}$ salt at $120^{\circ} \mathrm{C}$.

\begin{tabular}{ccccc}
\hline \hline Salt & $\begin{array}{c}\text { Initial mole fraction } \\
\text { of } 4_{1, \text { free }}\end{array}$ & $\mathrm{k}_{1}{ }^{*} 10^{2}\left(\mathrm{~min}^{-1}\right)$ & $\mathrm{k}_{2}{ }^{*} 10^{2}\left(\mathrm{M}^{-1} \mathrm{~min}^{-}\right.$ & $\mathrm{k}_{3}{ }^{*} 10^{2}\left(\mathrm{~min}^{-1}\right)$ \\
\hline$[\mathrm{Li}][\mathrm{TFSI}]$ & 0.007 & 0.03 & 4.0 & 6.3 \\
{$[\mathrm{Li}]\left[\mathrm{A}-\mathrm{SO}_{2} i P r F_{4}\right]$} & 0.037 & 0.19 & 4.1 & 8.0 \\
{$[\mathrm{Li}][\mathrm{A}]$} & 0.029 & 0.10 & 3.1 & 5.5 \\
{$[\mathrm{Li}]\left[\mathrm{A}-\mathrm{SiPrF}_{4}\right]$} & 0.050 & 0.13 & 0.6 & 5.6 \\
{$[\mathrm{Li}]\left[\mathrm{NO}_{3}\right]$} & 0.175 & 1.90 & 0.02 & 4.0 \\
\hline \hline
\end{tabular}




\section{Synthetic Methods.}
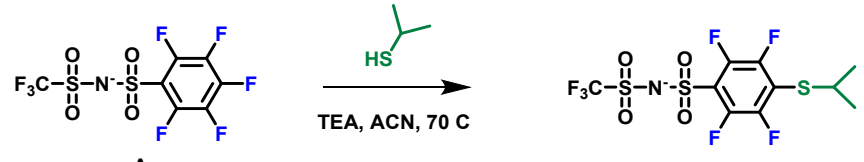

A-SiPrF : To a $40 \mathrm{~mL}$ vial equipped with a magnetic stirring bar were added $\mathbf{A}(0.90 \mathrm{~g}, 2.25 \mathrm{mmol})$, 2-propanethiol $(0.50 \mathrm{~mL}, 5.38 \mathrm{mmol})$, triethylamine $(0.75 \mathrm{~mL}, 5.38 \mathrm{mmol})$, and $20 \mathrm{~mL}$ acetonitrile. The mixture was stirred at $70{ }^{\circ} \mathrm{C}$ for $12 \mathrm{~h}$. After removing the solvent under vacuum, the residue was dissolved in $30 \mathrm{~mL}$ ethyl acetate, and washed with $1 \mathrm{M}$ hydrochloric acid $(1 \times 20 \mathrm{~mL})$, water $(1 \times 20 \mathrm{~mL})$ and brine solution $(2 \times 20 \mathrm{~mL})$. Then organic layer was dried over anhydrous sodium sulfate and concentrated in vacuum. The residue was purified by flash chromatography on silica gel with acetone/hexanes $(\mathrm{v} / \mathrm{v}=1 / 2)$ as the eluent to afford the product as a white solid $(0.94 \mathrm{~g}, 91 \%)$. ${ }^{1} \mathrm{H} \mathrm{NMR}(400 \mathrm{MHz}$, Acetone- $\left.d_{6}\right) \delta 3.64(\mathrm{p}, J=6.6 \mathrm{~Hz}, 1 \mathrm{H}), 1.30(\mathrm{~d}, J=6.7 \mathrm{~Hz}, 6 \mathrm{H}) .{ }^{13} \mathrm{C}$ NMR $\left(101 \mathrm{MHz}\right.$, Acetonitrile- $\left.d_{3}\right) \delta 149.51-146.13$ $(\mathrm{m}), 144.21(\mathrm{dd}, J=255.9,16.9 \mathrm{~Hz}), 124.52,120.66$ (q, $J=322.0 \mathrm{~Hz}), 118.2,39.75,23.16 .{ }^{19} \mathrm{~F} \mathrm{NMR}(376 \mathrm{MHz}$, Acetone- $\left.d_{6}\right) \delta-79.25,-135.40,-138.13 . \mathrm{MS}(\mathrm{m} / \mathrm{z})$ : Calc. for $\mathrm{C}_{10} \mathrm{H}_{7} \mathrm{NF}_{7} \mathrm{O}_{4} \mathrm{~S}_{3} \mathrm{Na}: 456.93$. Found (M-Na): 433.9 .

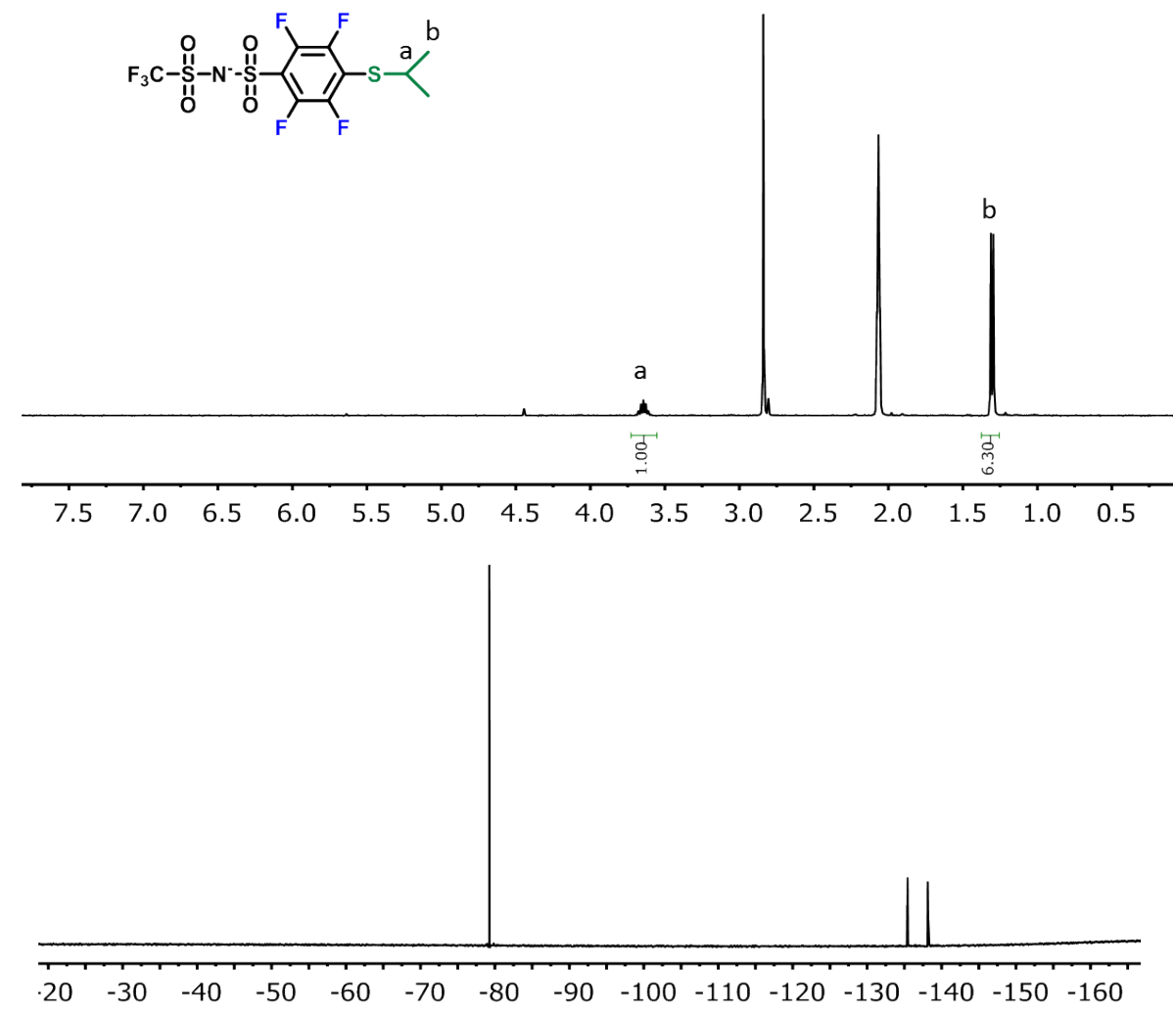




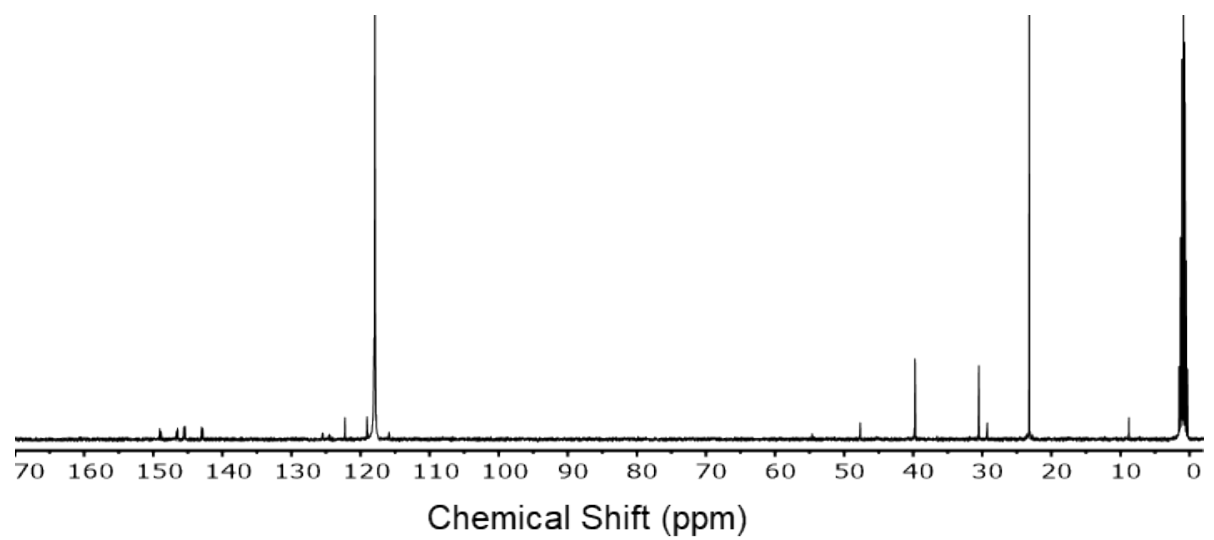

Figure S7. ${ }^{1} \mathrm{H},{ }^{19} \mathrm{~F}$, and ${ }^{13} \mathrm{C}$ NMR spectra for $\mathrm{A}-\mathrm{SiPrF}_{4}$

A-SOiPrF 4 : To a $20 \mathrm{~mL}$ vial equipped with a magnetic stirring bar were added $A-S_{i P r F}(0.45 \mathrm{~g}, 1.00 \mathrm{mmol})$, urea hydrogen peroxide $(0.38 \mathrm{~g}, 4.0 \mathrm{mmol}), 0.40 \mathrm{~mL}$ water, and $3.0 \mathrm{~mL}$ acetic acid. The mixture was stirred at room temperature for $48 \mathrm{~h}$. After removing most of the acetic acid under vacuum, the residue was extracted with $30 \mathrm{~mL}$ ethyl acetate and washed with water $(1 \times 20 \mathrm{~mL})$ and brine solution $(2 \times 20 \mathrm{~mL})$. Then organic layer was dried over anhydrous sodium sulfate and concentrated in vacuum. The residue was purified by flash chromatography on silica gel with acetone/hexanes $(\mathrm{v} / \mathrm{v}=1 / 1)$ as the eluent to afford the product as a white solid $(0.46 \mathrm{~g}, 97 \%)$. ${ }^{1} \mathrm{H} \mathrm{NMR}(400 \mathrm{MHz}$, Acetone- $\left.d_{6}\right) \delta 3.65(\mathrm{p}, J=6.7 \mathrm{~Hz}, 1 \mathrm{H}), 1.44(\mathrm{~d}, J=6.8 \mathrm{~Hz}, 3 \mathrm{H}), 1.26(\mathrm{~d}, J=6.8 \mathrm{~Hz}, 3 \mathrm{H}) .{ }^{13} \mathrm{C} \mathrm{NMR}(101 \mathrm{MHz}$, Acetonitrile$\left.d_{3}\right) \delta 145.45(\mathrm{dd}, J=269.9 \mathrm{~Hz}, 16.9 \mathrm{~Hz}), 145.75-142.54(\mathrm{~m}), 127.68,124.31,120.63(\mathrm{q}, J=321.9 \mathrm{~Hz}), 54.53,15.61$, 15.21. ${ }^{19} \mathrm{~F}$ NMR (376 MHz, Acetone- $\left.d_{6}\right) \delta-79.25,-136.42,-141.24$. MS (m/z): Calc. for $\mathrm{C}_{10} \mathrm{H}_{7} \mathrm{NF}_{7} \mathrm{O}_{5} \mathrm{~S}_{3} \mathrm{Na} 472.93$. Found (M-Na):: 450.0.
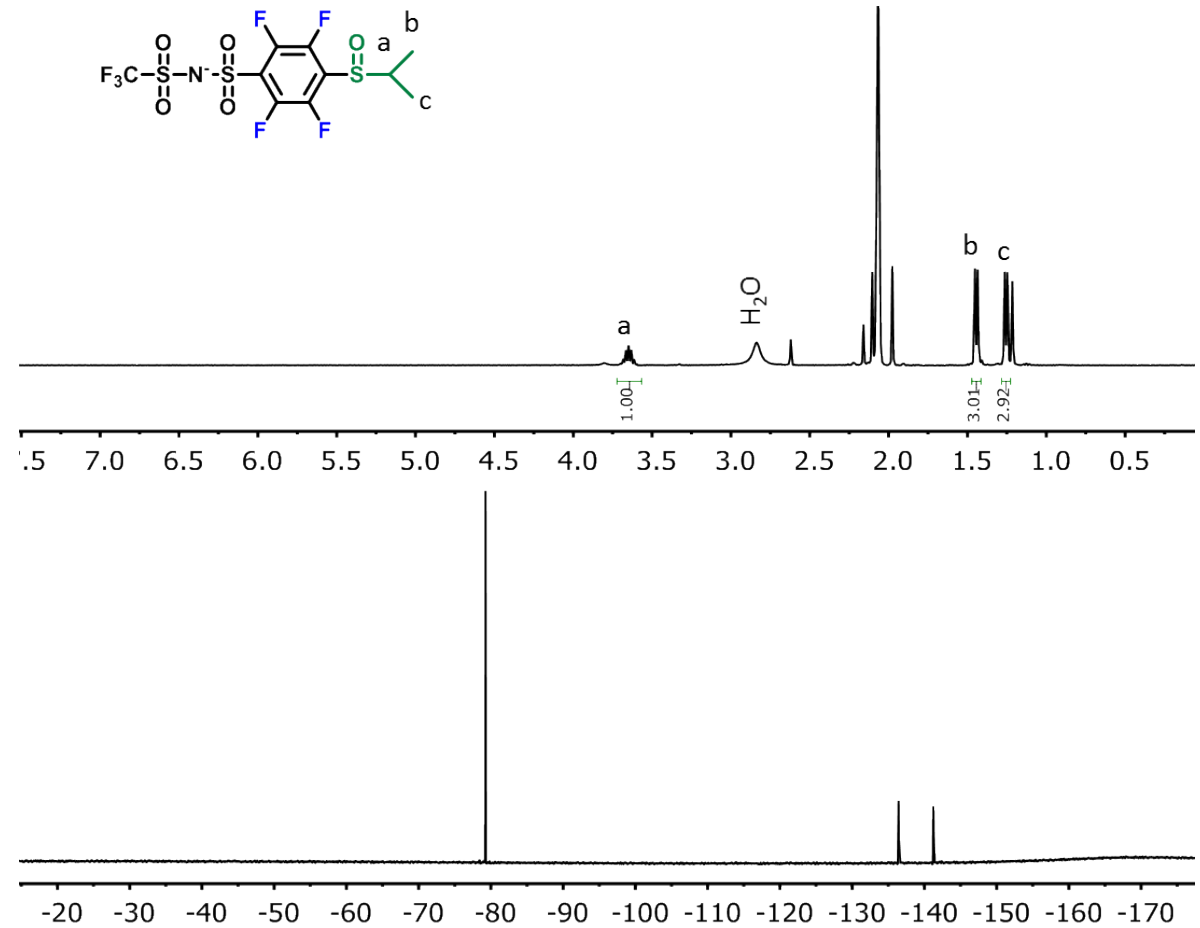


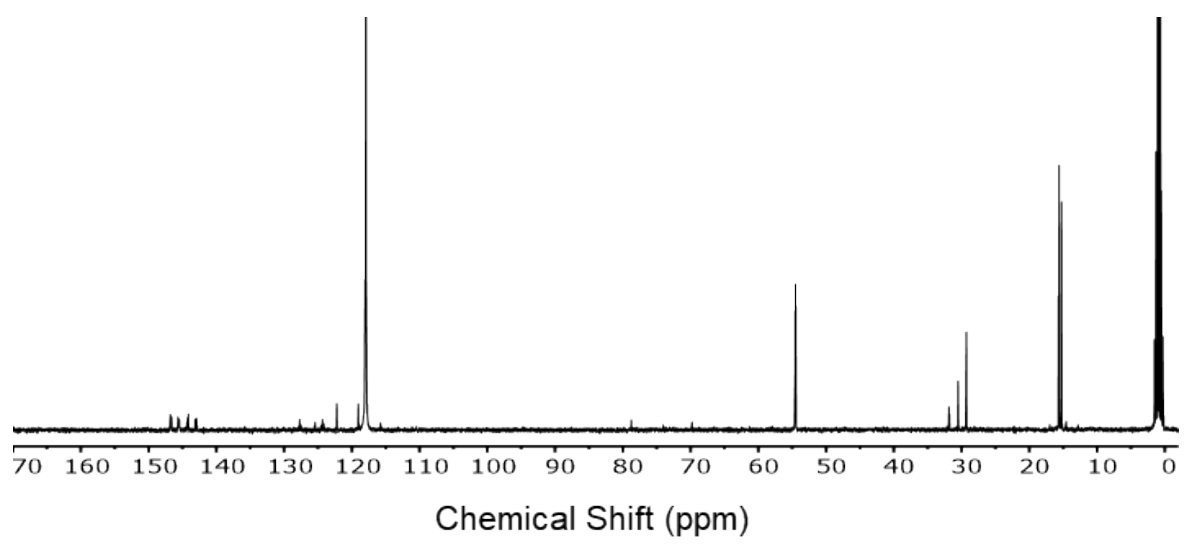

Figure S8. ${ }^{1} \mathrm{H},{ }^{19} \mathrm{~F}$, and ${ }^{13} \mathrm{C}$ NMR spectra for $\mathrm{A}-\mathrm{SOiPrF}_{4}$

$\boldsymbol{A}_{-} \mathrm{SO}_{2} \mathrm{iPrF}_{4}$ : To a $20 \mathrm{~mL}$ vial equipped with a magnetic stirring bar were added $A-\mathrm{SiPrF}_{4}(0.30 \mathrm{~g}, 0.67 \mathrm{mmol}), \mathrm{urea}$ hydrogen peroxide $(0.25 \mathrm{~g}, 2.70 \mathrm{mmol}), 0.30 \mathrm{~mL}$ water, and $2.0 \mathrm{~mL}$ acetic acid. The mixture was stirred at $50{ }^{\circ} \mathrm{C}$ for 24 h. After removing most of the acetic acid under vacuum, the residue was extracted with $30 \mathrm{~mL}$ ethyl acetate and washed with water $(1 \times 20 \mathrm{~mL})$ and brine solution $(2 \times 20 \mathrm{~mL})$. Then organic layer was dried over anhydrous sodium sulfate and concentrated in vacuum. The residue was purified by flash chromatography on silica gel with acetone/hexanes $(\mathrm{v} / \mathrm{v}=$ $2 / 3)$ as the eluent to afford the product as a white solid $(0.30 \mathrm{~g}, 91 \%) .{ }^{1} \mathrm{H}$ NMR $\left(400 \mathrm{MHz}\right.$, Acetone- $\left.d_{6}\right) \delta 3.64(\mathrm{p}, \mathrm{J}=$ $6.8 \mathrm{~Hz}, 1 \mathrm{H}), 1.42(\mathrm{~d}, J=6.8 \mathrm{~Hz}, 6 \mathrm{H}) .{ }^{13} \mathrm{C}$ NMR $\left(101 \mathrm{MHz}\right.$, Acetonitrile- $\left.d_{3}\right) \delta 147.62-145.67(\mathrm{~m}), 144.92-142.56(\mathrm{~m})$, 129.51, 120.54 (q, $J=321.7 \mathrm{~Hz}), 119.71,57.95,14.55 .{ }^{19} \mathrm{~F}$ NMR (376 MHz, Acetone- $\left.d_{6}\right) \delta$-79.28, -135.47, -137.66. MS $(\mathrm{m} / \mathrm{z})$ : Calc. for $\mathrm{C}_{10} \mathrm{H}_{7} \mathrm{NF}_{7} \mathrm{O}_{6} \mathrm{~S}_{3} \mathrm{Na:}$ 489.33. Found (M-Na): 465.9 . 


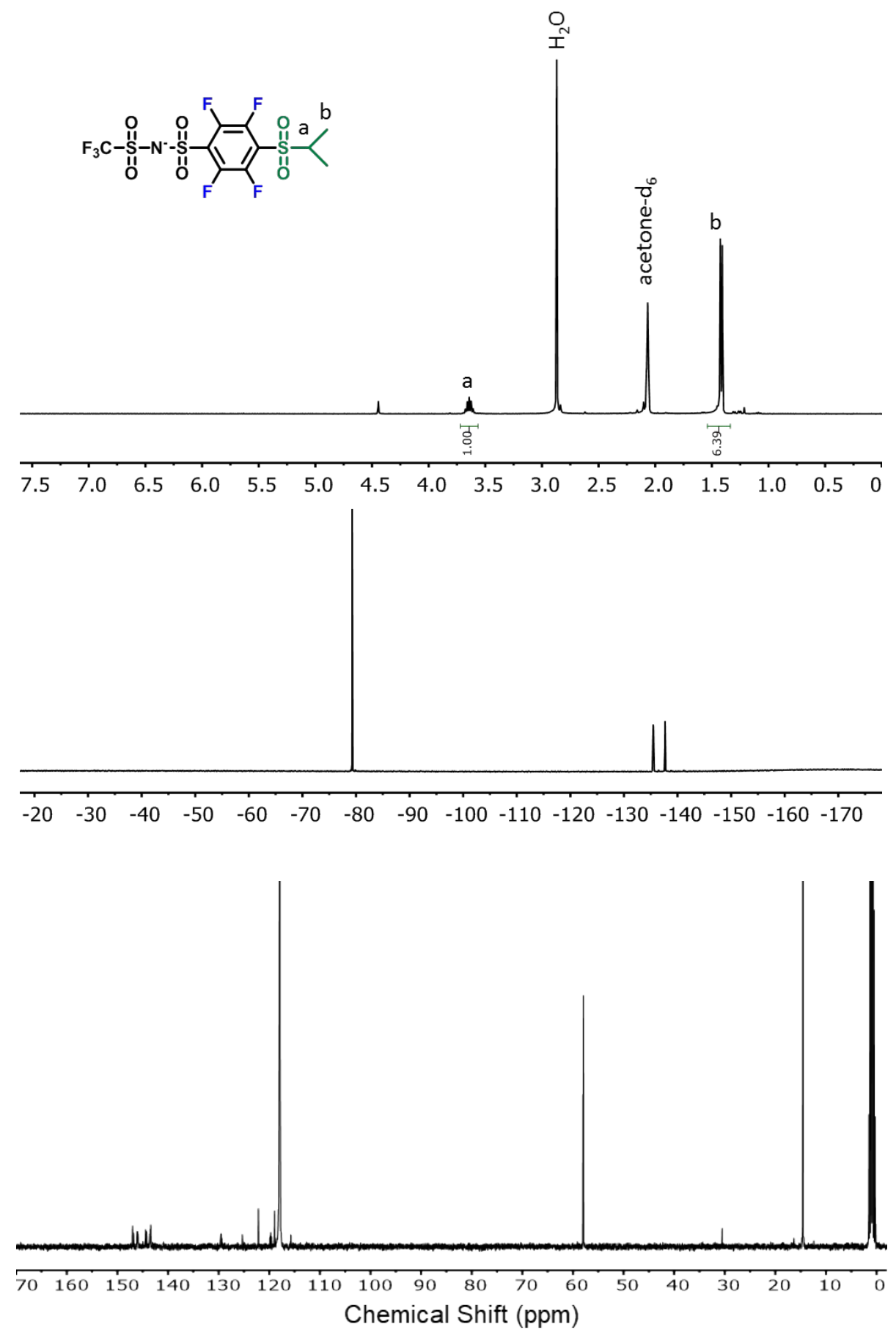

Figure S9. ${ }^{1} \mathrm{H},{ }^{19} \mathrm{~F}$, and ${ }^{13} \mathrm{C}$ NMR spectra for $\mathrm{A}-\mathrm{SO}_{2} \mathrm{iPrF}_{4}$

$A-S_{P i} r_{3} F_{2}$ : To a $40 \mathrm{~mL}$ vial equipped with a magnetic stirring bar were added dry 2-propanethiol (1.63mL, $\left.17.5 \mathrm{mmol}\right)$, sodium hydride $(0.46 \mathrm{~g}, 19.4 \mathrm{mmol})$, and $10 \mathrm{~mL}$ dry DMF under nitrogen. After stirred at $0{ }^{\circ} \mathrm{C}$ for $0.5 \mathrm{~h}$, the mixture was transferred dropwise to another $40 \mathrm{ml}$ vial which has been charged with $\mathbf{A}(1.56 \mathrm{~g}, 3.9 \mathrm{mmol})$ and $5 \mathrm{~mL}$ DMF first. The solution was quenched by adding $5 \mathrm{~mL} 1 \mathrm{M} \mathrm{HCl}$ aqueous solution after further stirred at room temperature for $2 \mathrm{~h}$. Then ethyl acetate $(100 \mathrm{~mL})$ was added to extract crude product and washed with water $(1 \times 50 \mathrm{~mL})$ and brine solution $(2 \times 50$ 
$\mathrm{mL}$ ). The organic layer was dried over anhydrous sodium sulfate and concentrated in vacuum. The residue was purified by flash chromatography on silica gel with acetone/hexanes $(\mathrm{v} / \mathrm{v}=1 / 2)$ as the eluent to afford the products as colorless viscous liquid (1.82 g, 82\%). ${ }^{1} \mathrm{H}$ NMR (400 MHz, Chloroform-d) $\delta 3.86-3.74(\mathrm{~m}, 1 \mathrm{H}), 3.73-3.65(\mathrm{~m}, 1 \mathrm{H}), 3.65-3.55$ (m, 1H), $1.38-0.98(\mathrm{~m}, 18 \mathrm{H}) .{ }^{13} \mathrm{C}$ NMR (101 MHz, Chloroform- $\left.d\right) \delta 158.43(\mathrm{~d}, J=245.0 \mathrm{~Hz}), 155.51$ (d, J = 252.7 Hz), $133.93(\mathrm{~d}, J=23.0 \mathrm{~Hz}), 131.97(\mathrm{~d}, J=14.9 \mathrm{~Hz}), 128.45$ (d, $J=24.3 \mathrm{~Hz}), 124.54$ (d, $J=26.0 \mathrm{~Hz}), 119.74$ (q, $J=321.7$ $\mathrm{Hz}$ ), 39.82 (d, $J=8.2 \mathrm{~Hz}$ ), 39.53 (d, $J=5.5 \mathrm{~Hz}$ ), 39.08 (d, $J=8.5 \mathrm{~Hz}), 23.17,23.08,22.87 .{ }^{19} \mathrm{~F} \mathrm{NMR} \mathrm{(376} \mathrm{MHz,}$ Chloroform- $d$ ) $\delta$-78.57, -94.45, -101.67. MS (m/z): Calc. for $\mathrm{C}_{16} \mathrm{H}_{21} \mathrm{NF}_{5} \mathrm{O}_{4} \mathrm{~S}_{5} \mathrm{Na:}$ 568.99. Found (M-Na): 546.0 .
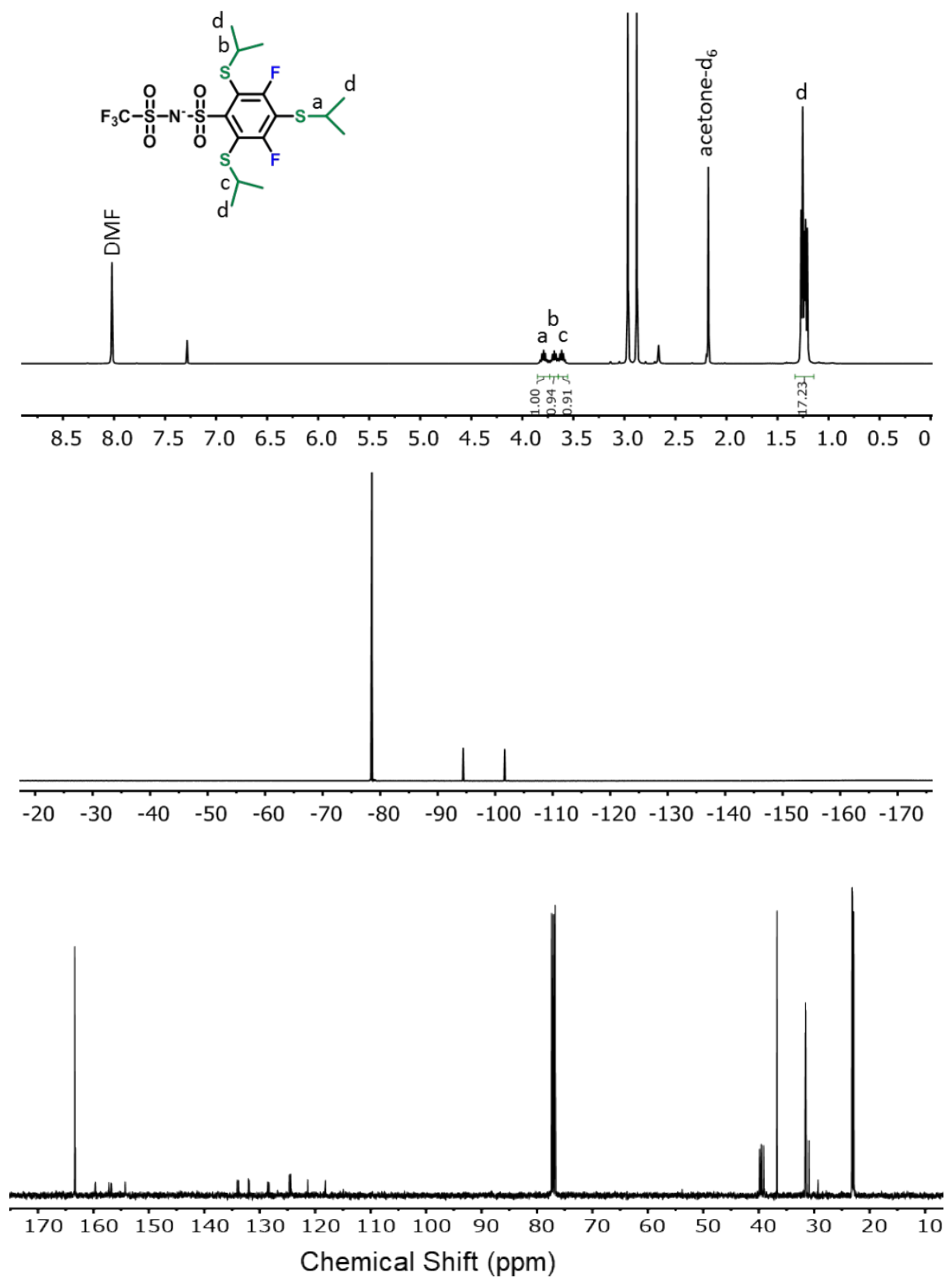

Figure S10. ${ }^{1} \mathrm{H},{ }^{19} \mathrm{~F}$, and ${ }^{13} \mathrm{C}$ NMR spectra for $A-\mathrm{SiPr}_{3} \mathrm{~F}_{2}$ 
$A-\mathrm{SO}_{2} \mathrm{iPr}_{3} \boldsymbol{F}_{2}$ : To a $20 \mathrm{~mL}$ vial equipped with a magnetic stirring bar were added $A-\operatorname{SiPr}_{3} F_{2}(0.20 \mathrm{~g}, 0.35 \mathrm{mmol})$, urea hydrogen peroxide $(0.39 \mathrm{~g}, 4.20 \mathrm{mmol}), 0.40 \mathrm{~mL}$ water, and $4.0 \mathrm{~mL}$ acetic acid. The mixture was stirred at $65^{\circ} \mathrm{C}$ for 12 $\mathrm{h}$. After removing most of the acetic acid under vacuum, the residue was extracted with $30 \mathrm{~mL}$ ethyl acetate and washed with water $(1 \times 20 \mathrm{~mL})$ and brine solution $(2 \times 20 \mathrm{~mL})$. Then organic layer was dried over anhydrous sodium sulfate and concentrated in vacuum. The residue was purified by flash chromatography on silica gel with acetone/hexanes $(\mathrm{v} / \mathrm{v}=$ $2 / 3$ ) as the eluent to afford the product as a white solid $(0.11 \mathrm{~g}, 48 \%)$. ${ }^{1} \mathrm{H}$ NMR $\left(400 \mathrm{MHz}\right.$, Acetone- $\left.d_{6}\right) \delta 4.58($ hept, $J$ $=6.9 \mathrm{~Hz}, 1 \mathrm{H}), 4.28$ (hept, $J=6.7 \mathrm{~Hz}, 2 \mathrm{H}), 1.54-1.37(\mathrm{~m}, 18 \mathrm{H}) .{ }^{13} \mathrm{C}$ NMR $\left(101 \mathrm{MHz}\right.$, Acetonitrile- $\left.d_{3}\right) \delta 156.17(\mathrm{dd}, J=$ 268.6, 29.4 Hz), 144.44 (d, $J=21.0 \mathrm{~Hz}$ ), 137.00 (dd, $J=70.8,19.3 \mathrm{~Hz}$ ), 135.24 (d, $J=20.4 \mathrm{~Hz}$ ), 120.48 (q, J=322.2 $\mathrm{Hz})$, 58.75, 57.22, 14.77, 14.61. ${ }^{19} \mathrm{~F}$ NMR (376 MHz, Acetone- $\left.d_{6}\right) \delta-78.45,-95.11,-98.74$. MS (m/z): Calc. for $\mathrm{C}_{16} \mathrm{H}_{21} \mathrm{NF}_{50} \mathrm{O}_{10} \mathrm{~S}_{5} \mathrm{Na:}$ 664.96. Found (M-Na): 641.9 . 

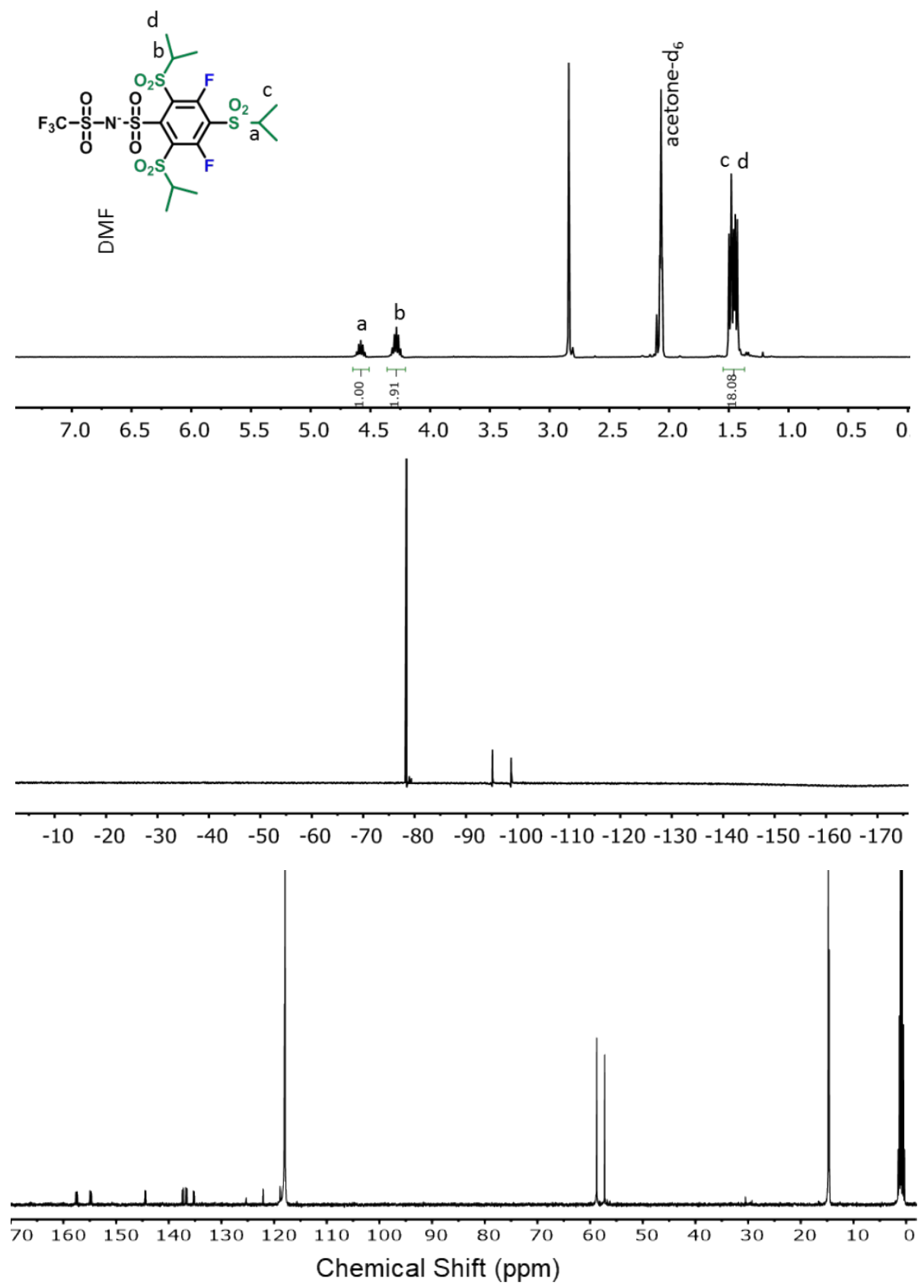

Figure S11. ${ }^{1} \mathrm{H},{ }^{19} \mathrm{~F}$, and ${ }^{13} \mathrm{C}$ NMR spectra for $\mathrm{A}-\mathrm{SO}_{2} \mathrm{iPr}_{3} \mathrm{~F}_{2}$

\section{Supplemental References.}

1. M. J. Gaussian 09, Revision A.02, Frisch, G. W. Trucks, H. B. Schlegel, G. E. Scuseria, M. A. Robb, J. R. Cheeseman, G. Scalmani, V. Barone, B. Mennucci and G. A. Petersson et al., 2016.

2. D. Becke, J. Chem. Phys., 1993, 98, 5648.

3. Lee, W. Yang and R. G. Parr, Phys. Rev. B, 1988, 37, 785-789.

4. A. E. Reed, R. B. Weinstock, and F. Weinhold, J. Chem. Phys., 1985, 83, 735-46. 
5. J. P. Foster and F. Weinhold, J. Am. Chem. Soc., 1980, 102, 7211-18.

6. M. Cossi, N. Rega, G. Scalmani and V. Barone, J. Comput. Chem., 2003, 24, 669-681.

7. V. Barone and M. Cossi, J. Phys. Chem. A, 1998, 102, 1995-2001.

8. L. Xing, O. Borodin, D. Smith and W. Li, J. Phys. Chem. C, 2011, 13896-13905.

9. S. Trasatti, Pure Appl. Chem., 1986, 58, 955-966.

10. M. J. Ziegler and J. D. Madura, J. Solution Chem. 2011, 40, 1383-1398.

11. K. Yoshida, M. Tsuchiya, N. Tachikawa, K. Dokko, M. Watanabe, J. Phys. Chem. C 2011, 115, 18384-18394.

12. J.E. Leffler and E. Grunwald, Rates and Equilibria of Organic Reactions, Wiley, 1963 (Dover reprint).

13. D. H. McDaniel and H. C. Brown, J. Org. Chem., 1958, 23, 420.

Appendix

$\% * * * *$ Directions for use $* * * *$

\%1) Input tspan and soln from experimental data. tspan is time. soln is the tga mass of G4 remaining converted into conc. (Assume salt doesn't evap)

\%2) Input the first data points from soln into the function at the bottom of the program for the inital concentration of G4 and salt

\%3) Modify the initial guesses to minimize the residual.

\%G4-liq -> G4-gas (k1)

$\%$ SIL $<->$ G4-liq + Salt $(\mathrm{k} 2 / \mathrm{k} 3)$

$\%$ note the different definitions of k's here than the rest of the SI and the main text

\%Initalize parameters

$\mathrm{EXP}=0$;

guess $=0$;

$\mathrm{k} 1=0$;

$\mathrm{k} 2=0$;

$\mathrm{k} 3=0$;

pbset $=0$;

presidual $=0$;

presnorm $=0$;

xinit $=0$;

$\mathrm{Y}=0$;

guess $=[0.07 ; 0.001 ; 0.006 ; 0.0007 ;] ; \%$ inital guess for k1, k2, k3, and initial [G4]liq

$\mathrm{lb}=[0 ; 0 ; 0 ; 0 ;] ; \%$ lower bound for fitting parameters is zero

$\mathrm{ub}=[]$

options = optimoptions('Isqcurvefit','MaxFunctionEvaluations',1000); 
[pbest,presnorm,presidual,exitflag,output $]=$ lsqcurvefit(@paramfun,guess,tspan,soln,lb,ub,options); \%fit ODEs in paramfun to data in soln. The fit is optimized by changing k1, k2, k3, and inital [G4]liq

$\% \% \% \% \%$ Plotting of solution to ODEs $\% \% \% \% \% \% \%$

\%initial conditions for ODE solver for plotting $\operatorname{xinit}(1)=\operatorname{pbest}(4) ; \%$ Optimized [G4] liq init $\operatorname{xinit}(2)=0 ; \%$ input value, init conc. of [G4] gas $\operatorname{xinit}(3)=\operatorname{soln}(1)-p b e s t(4) ; \%$ mol balance of G4 between free and SIL using optimized [G4] liq init

$\operatorname{xinit}(4)=\operatorname{soln}(1,2)-\operatorname{soln}(1)+\operatorname{pbest}(4) ; \%$ mol salt in the system (constant since we assume salt doesn't evaporate). Inital mol salt from solution minus salt in SIL

$\mathrm{k} 1=\mathrm{pbest}(1) ; \%$ optimized rate constants

$\mathrm{k} 2=\operatorname{pbest}(2)$;

$\mathrm{k} 3=\operatorname{pbest}(3)$;

$\mathrm{f}=@(\mathrm{t}, \mathrm{a})[-\mathrm{k} 1 * \mathrm{a}(1)+\mathrm{k} 2 * \mathrm{a}(3)-\mathrm{k} 3 * \mathrm{a}(1) * \mathrm{a}(4) ; \mathrm{k} 1 * \mathrm{a}(1) ;-\mathrm{k} 2 * \mathrm{a}(3)+\mathrm{k} 3 * \mathrm{a}(1) * \mathrm{a}(4) ; \mathrm{k} 2 * \mathrm{a}(3)-$ $\mathrm{k} 3 * \mathrm{a}(1) * \mathrm{a}(4) ;$; $\%$ Resolve systems of ODEs for plotting using optimized inputs.

$[\mathrm{T}, \mathrm{Y}]=$ ode45(f,tspan,xinit); \%solve ODEs with optimized parameters to obtain all concentrations

figure (1)

$\operatorname{subplot}(2,2,1)$

$\operatorname{plot}(\mathrm{T}, \mathrm{Y}(:, 3)) ; \% \mathrm{Y} 1$ is G4 liq, Y2 is G4 gas, Y3 is SIL, Y4 is Salt

$\mathrm{EXP}=\mathrm{Y}$

$\%$ process experimental data

$\operatorname{EXP}(:, 1)=\operatorname{soln}(:, 1)-\mathrm{Y}(:, 3) ; \%$ calcualted amount of free G4 based on the TGA data minus calculated SIL concentration

$\operatorname{EXP}(:, 2)=\operatorname{soln}(:, 1)-\mathrm{Y}(:, 1) ; \%$ calculated amount of SIL based on the TGA data minus calculated free G4 concentration

$\operatorname{EXP}(:, 3)=-(\operatorname{soln}(:, 1)-\operatorname{soln}(1)) ; \%$ experimental amount of evaporated G4

hold on

plot(tspan, $\operatorname{EXP}(:, 2))$;

legend SIL ExperimentalSIL

xlabel 'Time (min)'

ylabel 'Concentration (M)'

hold off

subplot(2,2,2) 
$\operatorname{plot}(\mathrm{T}, \mathrm{Y}(:, 1))$;

hold on

$\operatorname{plot}(\mathrm{T}, \mathrm{Y}(:, 2))$;

plot(tspan,EXP(:,1));

plot(tspan, $\operatorname{EXP}(:, 3))$;

legend(\{'G4_1_i_q', 'G4_g_a_s', 'ExperimentalG4_1_i_q',

'ExperimentalG4_g_a_s' ,'Location','northwest')

xlabel 'Time ( $\mathrm{min})^{\prime}$

ylabel 'Concentration (M)'

hold off

subplot $(2,1,2)$

plot(T,presidual(:,1))

legend Residual

xlabel 'Time (min)'

ylabel 'Residual'

fprintf('Optimized k1: \%f, k2: \%f, and k3: \%f,',pbest(1:3))

function pos $=$ paramfun $(\mathrm{x}$, tspan $)$

$\mathrm{k} 1=\mathrm{x}(1) ; \%$ passed from optimization function

$\mathrm{k} 2=\mathrm{x}(2) ; \%$ passed from optimization function

$\mathrm{k} 3=\mathrm{x}(3) ; \%$ passed from optimization function

$\mathrm{xt} 0(1)=\mathrm{x}(4) ; \%$ initial mol free G4 in the liquid, passed from optimization function

$\mathrm{xt} 0(2)=0 ; \%$ initial mol gas G4

$\mathrm{xt0}(3)=2.72124378-\mathrm{xt0}(1) ; \%$ input initial TGA mass converted to G4 concentration from

soln(1), mol balance of G4 between free and SIL

$\mathrm{xt0}(4)=2.769591183-\mathrm{xt0}(3) ; \%$ input initial salt concentration from $\operatorname{soln}(1,2)$ concentration free salt in the system, mol balance between SIL and free salt

$\mathrm{f}=@(\mathrm{t}, \mathrm{a})[-\mathrm{k} 1 * \mathrm{a}(1)+\mathrm{k} 2 * \mathrm{a}(3)-\mathrm{k} 3 * \mathrm{a}(1) * \mathrm{a}(4) ; \mathrm{k} 1 * \mathrm{a}(1) ;-\mathrm{k} 2 * \mathrm{a}(3)+\mathrm{k} 3 * \mathrm{a}(1) * \mathrm{a}(4) ; \mathrm{k} 2 * \mathrm{a}(3)-$

$\mathrm{k} 3 * \mathrm{a}(1) * \mathrm{a}(4) ;]$;

$[\sim$, result $]=$ ode45(f,tspan,xt0); \%return the results of the solved ODEs to the optimization function to check against the experimental data (soln)

$\operatorname{pos}(:, 1)=$ result(:(1)+result(:,3); \% recombine mol free G4 and mol SIL to fit molar TGA data $\operatorname{pos}(:, 2)=\operatorname{result}(:, 3)+\operatorname{result}(:, 4) ; \%$ recombine mol SIL and mol Salt to fit vs known amount of salt.

end 